\title{
Conception of Lifelong Learning at the Faculty of Economics, Technical University of Ostrava, in the Field of Management
}

\author{
Petra Horváthová, Member, IACSIT and Andrea Čopíková
}

\begin{abstract}
The paper describes the implementation of e-learning educational program in the field of Management at the Faculty of Economics, VŠB-Technical University of Ostrava. Furthermore, it describes a form of educational program, its goals and the final target groups for which the program is designed, benefits of this type of education for its graduates, characteristics and organization, study materials and the achieved outcomes. The aim of the paper is not only to inform on the successful improvement of lifelong learning at the Faculty of Economics, VŠB-Technical University of Ostrava, but especially to serve as an inspiration for other interested persons working towards similar ends.
\end{abstract}

Index Terms - Conception, educational module, e-learning, lifelong learning.

\section{INTRODUCTION}

A present, quickly changing and dynamic environment accelerates the scientific and technical progress. It appears that in spite of growing overall length of education the acquired knowledge and skills are not any longer sufficient for a professional career lasting three or four decades. That is why a continuous building of skills and knowledge throughout the life is absolutely necessary. And it is just lifelong learning that seems to be a very appropriate solution of this situation.

This type of education offers people of various ages a number of learning opportunities not only through formal institutions (secondary schools, universities....), but also at their workplaces, at home or through activities in their free time.

In the last few years, E-learning can be considered as most developing and most often used type of lifelong learning. It uses a whole number of instruments - CD ROM, websites, PDA, MP3; discuss boards, e-mail, special software, chat, simulation, and assessment through PC, games, educational animations, video sequences and etc., including their combinations.

This type of lifelong learning is of great interest among potential students mainly due to its considerable flexibility, relatively easy communication (between students and teachers, among students themselves), and a probable adaptation to students' requirements. Potential students have

Manuscript received September 11, 2011; revised October 26, 2011.

The authors are with the VŠB-Technical University of Ostrava, Faculty of Economics, Department of Management, Sokolská 33, 70121 Ostrava 1, Czech Republic (phone: 00-420-59 699 2442; fax: 00-420-59 110 026; e-mail: petra.horvathova@vsb.cz); (e-mail: andrea.copikova@vsb.cz). an option to choose their own pace, which facilitates their study.

In 2006, a project of e-learning education in the field of Management was created by a research team made up of members of the Department of Management at the Faculty of Economics, VŠB-TU Ostrava, just as the immediate response to the demand for such type of education mainly due to growing demands made on organizations and their employees in the process of integration into the EU.

\section{THE Aim OF THE Program}

Creation, elaborating, verification and implementation of the original modular e- learning educational program initiated and helped to arouse interest of the final target groups in the efficient way of education contributing to the increase of their competence, relevant to their needs, interests and drawbacks that were identified at the final target groups, and to their potentialities to be further educated at universities.

Another aim of the program was also to contribute to taking over individuals' responsibility for their personal advancement, self-sufficiency, and self-fulfillment in the context of developing civil society, furthermore to the application of equal opportunities policy, social responsibility and business ethics while the sustainable development of the society was respected [2]. The program was to assist in the increase of knowledge ability, a level of education, and the overall awareness of persons within the final target groups. Its role was positively to influence their behavior in the organization and to increase the level of their professionalism.

Among goals of the project there were also reformulation and integration of the present teaching materials focused on the efficient self-reflection of participants in the educational process and on the development of achievements and qualifications serving to the enhancement of their organizational and managerial qualifications into an internally consistent, interconnected, compatible, practically orientated and understandable collection of knowledge and instructions. Interactive study environment was to create a base for further development of educational program [8].

\section{THE FINAL TARGET GROUPS}

The final target groups which the project was aimed at were as follows:

- academic staff at universities, scientific or research staff at 
institutions which were part of universities, teachers at secondary and grammar schools,

- Graduates from universities and institutions of higher learning who wanted to be further educated and to improve their qualification by acquiring professional knowledge which they had not acquired in the way of continual education and for who the form of e-learning education and tutorials was convenient (in that group there were also temporarily unemployed graduates from universities who wanted to strengthen their own competitiveness on the labor market),

- Other people interested in further study at university managers and companies employees, entrepreneurs, persons disadvantaged on the labor market).

If the target group wanted to take part in the designed educational program then it was necessary for its members to achieve at least secondary education completed with a school-leaving examination.

\section{Shape of THE PROGRAM}

Creation and implementation of e-learning educational program at the Faculty of Economics, VŠB-Technical University of Ostrava, took place within the project of 'Conception of Lifelong Learning in the Field of Management' which was co-financed by the European Social Fund (Operational Program of Human Resources Management) and by the funds of the Czech Republic state budget. The implementation of that project took place in the period from 01.01.2007 to 30.06.2008. The project was focused on the improvement of the level of lifelong learning at the Faculty of Economics, VŠB-Technical University of Ostrava, and on the creation of a new conception of lifelong learning in the field of Management that extended the offer of already existing educational products [8].

This educational e-learning program was drawn up as an open unit construction system encompassing a number of interconnected educational modules where participants in the course had an option flexibly to choose such a structure of modules that enabled them to create for themselves a course 'made to measure' . Fig.1 graphically illustrates this situation.

Individual modules were focused on:

- the increase of personal potential and self-development management,

- up-grading of management,

- strategic management of the organization,

- management of organizational changes,

- operational management,

- financial and cost management,

- human resources management,

- Strengthening of social responsibility and other areas of self-development.

The actual shape of the educational program was based on the identification and specification of educational needs of the final target groups, their interests, knowledge and skills deficits and further obstacles on the way to the extension of possibilities of their placement in organizations and a better use of their abilities or, as the case maybe, the use of their competitiveness on the labor market in the conditions of market economy.
This identification and specification of needs was carried out as a pilot research involving potential participants interested in the suggested kind of education (final target groups). Within a pilot survey by means of questionnaires 60 respondents from the final target groups were addressed. A total of 42 questionnaires returned, which represents $70 \%$ of the total number of posted questionnaires. With regard to the number of cooperating respondents, the informative power of survey of the initial piloting can be considered as satisfactory.

$\begin{array}{ll}\text { M } 1 & \text { Development of Personal Potential } \\ \text { M } 2 & \text { Fundamentals of Management } \\ \text { M } 3 & \text { Strategic Management of the Organization } \\ \text { M } 4 & \text { Management of Changes in the Organization } \\ \text { M 5 } & \text { Human Resources Management } \\ \text { M 6 } & \text { Operations Management } \\ \text { M } 7 & \text { Financial Management of Organization } \\ \text { M } 8 & \text { Marketing } \\ \text { M } 9 & \text { Basic Management Skills } \\ \text { M 10 } & \text { Environment of the European Union } \\ \text { M 11 } & \text { Creative Solutions of Problems } \\ \text { M 12 } & \text { Management of Innovation } \\ \text { M 13 } & \text { Organizational Culture } \\ \text { M 14 } & \text { Performance Management and Motivation of } \\ \text { M 15 } & \text { Effective Communications } \\ \text { M 16 } & \text { Quality Management etc. } \\ \text { M 17 } & \text { Environmental Management of Organization } \\ \text { M 18 } & \text { Management of Risk and Crises } \\ \text { M 19 } & \text { Business Dealings } \\ \text { Legend: } & \end{array}$

Merspective considered modules within an integrated concept

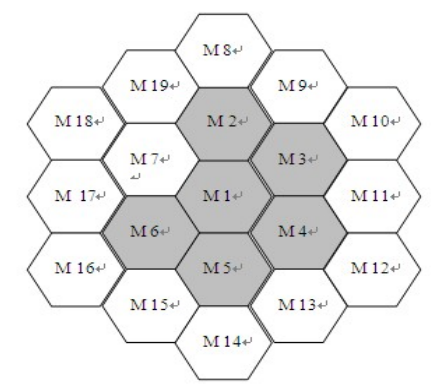

Fig. 1. Educational program structure and its modules (own processing)

On the basis of the pilot research outcomes, the first original structure of e-learning educational program and its modules had been designed. Fig. 1 graphically illustrates this situation.

Then in order to determine preferences of interest in this newly created program, a survey on a broader spectrum of the final target groups was carried out from January to April 2007. Realization of this survey took place from the beginning of 2007 to the middle of April 2007. Like in the pilot survey also in this case a survey by means of questionnaires was used. Respondents were offered 19 educational (training) modules M 1, M 2,....M 19. Fig.1 graphically illustrates this situation.

Interest in individual models was assessed on the even scale from 1 (lack of interest) up to 4 (I am interested in). Questionnaires were distributed to respondents in two ways, by means of email (a total number of 2500 pieces of questionnaires were sent - the rate of return was $6 \%$ ), and on the basis of personal, individual contact of a member of the research team and a possible interested person in the 
educational program from the final target groups (the rate of return was $100 \%$ ). 201 questionnaires were forwarded for mechanical data processing through the use of SPSS Base 15.0 program.

By the survey it was found out that the respondents had showed interest in all designed modules. It means that any of the submitted modules did not receive a below-average assessment of preference. The addressed representatives of the final target groups showed the highest interest in the following modules (put in order according to the highest interest to the lower while mean values may range from 0 up to 4 interval).

1. Effective communication (3.23)

2. Performance management and motivation of people (3.18)

3. Business dealings (3.04)

4. Development of personal potential (2.96)

5. Basic managerial skills (2.91)

6. Basics of management (2.88)

7. Human resources management (2.84)

8. Strategic management of organization (2.80)

9. Operational management of organization (2.76)

10. Management of organizational changes (2.71)

11. Marketing (2.71)

Note: Educational modules that are highlighted in bold letters are the modules which were included into the educational program.

From the above-mentioned general summary it is obvious that six modules that were included in the initial composition of the education program (see above-mentioned scheme) rank among those in which the respondents as a whole showed the greatest interest. As a conclusion we can say that a proposal of composition of e-learning educational program worked out by a research team consisting of members of the Department of Management at the Faculty of Economics, VŠB-TU Ostrava, was correct.

The content of individual modules was as follows:

Module M 1 - Development of Personal Potential - The target of this initial educational module was to acquaint students with the basic psychological knowledge of individual man's work and development potential and the significance of their self-reflection for their self-fulfillment. Getting acquainted with the methods of self-awareness and self-development of individual's personality was also part of the module. Students were encouraged to make a decision on how they want to strengthen their self-containment and personal prosperity by increasing their competences, capacity for action and competitiveness. The study of the module showed the students how to proceed, what they should focus on, and what steps they should take to be able to put into practice the strategy of their personal development, to achieve their personal goals and at the same time to contribute to the organizational efforts and synergic effect of the organization in which they operate [7].

M 2 - Fundamentals of Management - This educational module defined the role of management in the organization and explained the basic managerial categories and concepts. It acquainted students with the roles of a manager, his profile, with the contents of individual managerial acting (planning, organizing, leadership, control) and with the principles of their quality fulfillment. Part of the module was focused on presenting students with knowledge and experience from the historical development of managerial conceptions and, of course, the current and modern trends in managerial conceptions and approaches were especially emphasized [5].

M 3 - Strategic Management of the Organization - the Module informed students on the issues of strategic management and used concepts, on the significance of strategy for the organization, and on the principles of strategic management and thinking. It provided a survey of strategic management models gaining grounds. Starting points of economic forecasting and the issues of prognoses were explained in the module as well as the interrelationship between prognoses and a strategic plan. The study text explained a formulation of organization's mission, visions and philosophy. It showed methods of the external and internal analysis. Emphasis was laid on knowledge of typology of strategies and the ability to choose a suitable strategy. At the end of the educational module the issues of strategy implementation were mentioned, especially the main principles of a new strategy introduction - management of a strategic change, impacts of implementation on the management process, corporate structure and on both organizational culture and communication [6].

M 4 - Management of Changes in the Organization - This module offered students' knowledge of when it is and when it is not necessary to think about changes, it highlighted critical points in the management of changes among which the most sensitive and the most risk spot are people who are involved in them. The module pointed to how and by what people may be influenced in the process of implementing the changes so that they support them and do not offer pointless resistance. Emphasis was laid on consistent informing on everything that is connected with a change, which would facilitate a preparation and implementation of changes so that their results could have long-term effects. Important were recommendations how to proceed in managing the most frequent changes and also in the introduction of radical changes. That is why it was necessary to explain what the process consists in and how the process maps are created. It was interesting for students to get acquainted with the mistakes the managers most often make at managing the changes and with the recommendations how to avoid them [8].

M 5 - Human Resources Management - The module was focused on understanding the power and significance of human resources management which are becoming a decisive resource for success and development of the organization in a dynamically changing environment. The aim is to build a cohesive social system respecting ethics and the efficiency of investment poured into it including the optimum and productive deployment of people in the system [4].

M 6 - Operations Management - This educational module took aim at operational management and the students were trained for a role of businessman that is how to design, organize and manage individual organizational processes serving the implementation of organizational strategy in order to meet criteria of effectiveness and economy. Also practically applicable knowledge of operational planning and 
operational optimization of organizational processes and technological management, and bottlenecks of operational management, quality control and other aspects of operational management were part of the module [3].

As regards the respondents, by their analysis according to the activity of the organization in which they work, their specialization, held positions, and the highest level of education attained it was found out that the respondents mostly worked in the field of services (37\%), middle management (42\%), and TOP management (33\%), economic professional specialization prevailed $(38 \%)$, and they were aged under 35 years $(47 \%)$.

As regards individual target groups, the sequence of their interest in training (educational) modules differs, but these target groups consider all six basic modules of the educational program as priorities.

\section{BENEFITS OF THE TARGET GROUPS}

The Completing of the e-learning educational program helped its participants from the final target groups to show various possibilities of how to develop their organizational qualifications or competitive skills as an important precondition for their personal prospects and prosperity in the market social-economic environment.

Participants in the educational program gradually acquired a number of knowledge from various thematic spheres. At the same time, with regard to the flexibility and modularity of the program they were allowed to choose the extent and focus of their self-improved activities.

After a successful completion of the module $M 1$ Development of Personal Potential, a graduate was able:

- easier to direct his further self-development within his organizational integration with regard to his personal capabilities and ambitions,

- with a deeper motivation to develop his organizational capabilities, understanding managerial approaches and methods enabling him to achieve higher quality and work efficiency; he will be able to determine specific ways in which he should proceed at enhancing his capabilities, employability and personal prosperity.

After a successful completion of the module M 2 Fundamentals of Management, a graduate was able:

- to assess and improve his dispositions for performing the job of a manager,

- to contribute to the target focusing of people behavior in line with the goals of the organization,

- to employ traditional as well as modern instruments of managerial work,

- to exercise individual managerial powers more efficiently,

- to recognize causes of people behavior and to use adequate instruments to the stimulation of their work performance,

- carefully to choose the style of leadership relevant to the concrete situation and to the characteristics of subordinates or colleagues.

After a successful completion of the module M 3 Strategic Management of the Organization, a graduate was able:

- to formulate mission, visions and philosophy of the organization,

- to specify organization's goals,
- to prognosticate the development of industrial environment,

- to apply analytical methods of strategic analysis,

- to be aware of impacts on the operation of the organization resulting from the introduction of a newly chosen strategy.

After a successful completion of the module M 4 Management of Changes in the Organization, a graduate was able:

- to understand the nature and causes of changes in the organization,

- to be aware of various roles of persons involved in the process of changes and how they cope with such changes,

- to understand how differently people may react on changes and how to guide them appropriately,

- to recognize causes which do not allow people to support a change and to show methods of how to deal with such resistance,

- to prepare and then to implement the intended organizational changes by using various models,

- to understand what reengineering is, at what moment to consider it and how to be ready for it,

- to understand what mistakes a manager may make in launching the changes (particularly those which are radical) and how to avoid them.

After a successful completion of the module M 5 Human Resources Management, a graduate was able:

- to apply theoretical knowledge into concrete forms of behavior on the labor market (search for a new job, recruitment process, training and retraining), and to understand demands on work behavior in the market economy,

- to recognize specifics and differences within the European Union, to strengthen the identification with the role of being employed or with the role of employing,

- to determine and understand personnel activities which practitioners in the field of human resources management deal with,

- to acquire social skills in searching for jobs on the labor market and thus to increase self-esteem of disadvantageous groups on the labor market so that they become more active candidates for a job.

After a successful completion of the module M 6 Operational Management, a graduate was able:

- to be well informed about advanced methods of operational planning and management applied in relation to the organizational business strategy,

- to achieve effective removal of 'bottlenecks' and to increase efficiency and economy of all operational processes, - to take a positive attitude to the improvement of organizational operation with regard to the future demands on the organization.

Completion of the educational program brought the final target groups the increase of competitiveness on the labor market, which was a contribution to the decrease of unemployment especially of those who had been disadvantaged on the labor market in the environment of market economy.

A formal aspect of graduation from the educational program was obtaining a certificate. Fig. 2 shows the form of a certificate. This depended on the success of participants in 
passing the final examination in the module/modules which the course was composed of. The form of the examination was specified by the director of the appropriate module. The study was provided free of charge [8].

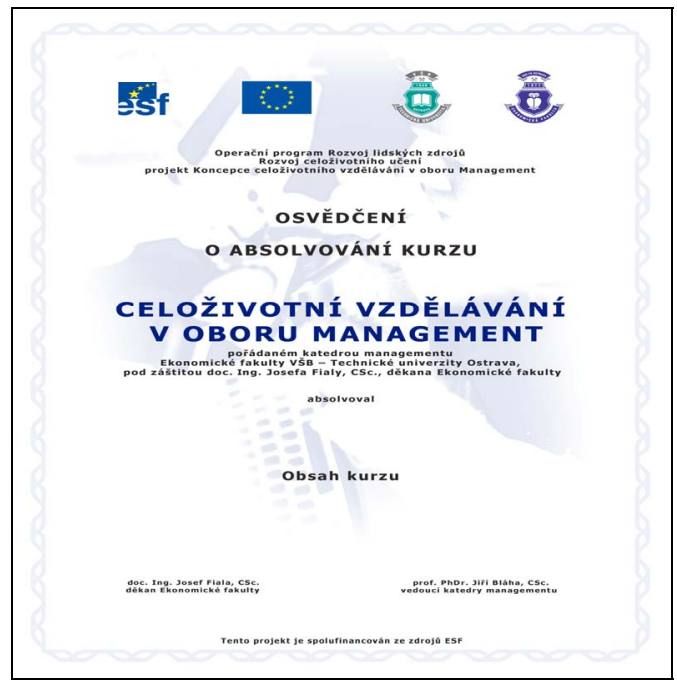

Fig. 2. Certificate

\section{CHARACTERISTICS AND ORGANIZATION OF EDUCATION}

Participants of e-learning educational program had an option individually to choose one or more modules from the offer and in this way to create their own course so that the choice could meet their concrete conditions and requirements and a learner could make use of all advantages of that type of education to the maximum.

One of the requirements placed on learners to be admitted to e-learning education was at least secondary education completed by a school-leaving examination and also their motivation to study in that untraditional form of instruction. Among technical requirements there was student's access to a computer and the internet; at least minimum practical experience in information technologies was then a necessity. Communication concerning teaching between the e-lecturer/tutor and the learner and mutual communication among students took place in the electronic way (by means of e-mail, chat, e-conferences, discussion forums, virtual classes and the like), most often in the environment of web, in the combination, however, of three tutorials which were to ensure not only a physical contact among learners and e-lecturers/tutors involved in individual modules but also to guarantee the achievement of learning objectives and a successful run of study.

E-learning educational program used a combination of two learning methods (so-called blended learning) which was the method of standard teaching with the method of e-learning teaching.

Standard teaching consisted of three tutorials introductory, control and final. Those tutorials took place in real time in which all learners including their e-lecturer/tutor were at the same place at the same time, e.g. in a classroom and thus they simultaneously received transmitted experience and they could mutually react.

In the course of e-learning teaching, every learner individually chose his/her pace and the way of receiving information, the kind of discussion with their e-lecturers/tutors as well as with other learners, and the way of knowledge testing so that the schedule of instructions set by a guarantee of the module or, as the case might be, by a lecturer/tutor at particular tutorials could be observed. As a disadvantage appeared the impossibility to react mutually at the same time. The focus of such type of teaching was e-learning educational modules in the electronic shape and learners' teach yourself study.

\section{STUDY AND OTHER MATERIALS}

E-learning education included two basic types of study materials. On-line documents using LCM MOODLE in IS/IT environment of the Faculty of Economics, VŠB-Technical University of Ostrava, served as the first type. In the accessible educational system of the Faculty the students found study materials to the modules, discussion forums, a virtual class with which they communicated the e-tests and diagnostics, control questions and etc. Learning texts on a CD-ROM that served to learners in case they did not have an opportunity to be just connected to the web were the second type of study materials.

Along with the on-line access, a common module called Lifelong Learning in the Field of Management was available for the students. By means of that module topical information on just running modules, a dictionary of the basic concepts of electronic education, a dictionary of the basic concepts used in professional modules, a Czech-English dictionary of most often used concepts, contacts to lecturers/tutors, references to other study literature and related sources and others were delivered. Also a simple guide through LCMS MOODLE environment provided important information. From that common module learners had a chance on-line to enter by them elected special modules (they were also allowed directly to enter specialist modules).

Furthermore, www pages of educational program were made accessible within which the students of individual modules had a possibility to obtain information on all matters concerning the educational program.

\section{The StATE OF Program IMPLEMENTATION}

From November 2007 to February 2008, a test operation of two modules was conducted, M 5 Human Resources Management, and M 4 Management of Changes in Organization. Altogether there were 35 participants who attended and completed the modules. From March 2008 to June 2008 the very professional training of target groups took place within the all offered modules. Altogether 114 participants completed this kind of education some of them obtained a certificate of completing the study in two or even three modules.

The whole project was concluded by a festive colloquium in June 2008.

\section{CONCLUSION}

The above-described e-learning educational program has 
brought a number of new elements into the present portfolio of educational activities provided by the Faculty of Economic, VŠB-Technical University of Ostrava.

It was especially a practically focused modular university educational program distinguished from others by a broad availability and high flexibility and interactivity enabling interested persons from the final target groups to choose a most suitable alternative of their self-improvement according to their own individual needs, interests and requirements.

The educational program was compatible with other educational activities at the university. Its outstanding features were a practical utilization, consistency and a systemic interconnection of individual modules, economy, comprehensibility, and the international comparability. With regard to the e-learning form of the program there was a possibility of learners' distant participation and interaction by means of electronic media, which allowed an equal access to taking part in that kind of study even to persons with limited possibilities of attending school.

Interactivity of the program ensured by a combination of e-learning form together with providing written study texts, tutorials, testing of acquired knowledge, workshops and accompanying publications was the essential innovative element. Educational program took into consideration a possibility of accommodating to learners' requirements.

A modular conception of the program together with on feedback based management of further development on the basis of a close cooperation with learners ensured a high adaptability of educational program to the needs of practice.

Openness of the unit construction educational system allowed its further development offering a possibility of widening the program by other considered modules. The project was based on needs of the final target groups and was outlined in such way so that it could contribute to the increase of knowledge ability, civil, economic and language literacy [8].

At present the Faculty of Economics, VŠB-Technical University of Ostrava, considers launching a second run of the program extended by modules focused on financial management of organizations and marketing.

The successfulness of the above-described program implementation might become a constant inspiration for other universities that want to achieve higher quality of the offered lifelong learning. The authors of the article will be pleased if this happens and they are ready to answer any question concerning the described program.

\section{REFERENCES}

[1] Burke, W. W. Organization Change: Theory and Practice, 1st ed. Los Angeles: Sage Publications, 2004, pp. 221-228.

[2] Certo, S. C., Peter, J. P. Strategic management: Concepts and Applications, 2nd ed. New York: McGraw-Hill, 1991, pp. 811-820.

[3] Dilworth, J. B. Operations Management: Providing value in Goods and Service, 3rd ed. Fort Worth: Dryden Press, 2000, pp. 558-599.

[4] Graham, H.T., Bennett. R. Human Resource Management, 7th ed. London: Macdonald \& Evans, 1992, pp. 92-116-.

[5] Koontz, H., Weihrich, H. Essentials of Management, 5th ed. New York: McGraw-Hill, 1990, pp. 21-38.

[6] Mikušová, M. "The practice of crisis management and training of managers at the turn of the millennium (Praxe krizového rízení a príprava manažerů na přelomu tisíciletí)", Aula, vol. 9, pp. 11-18, 2001.

[7] Murdock, A., Scutt, C. N. Personal Effectiveness, 2nd ed. Oxford: Butterworth-Heinemann, 1997, pp.116-128.

[8] The application form for financial aid from the OP RLZ (project name: Conception of lifelong education in the field of management, Registration Number: CZ.04.1.03/3.2.15.3) 